Article

\title{
Sustainable Water Distribution Strategy with Smart Water Grid
}

\section{Seongjoon Byeon ${ }^{1, *}$, Gyewoon Choi ${ }^{1}$, Seungjin Maeng ${ }^{2}$ and Philippe Gourbesville ${ }^{3}$}

1 Department of Civil and Environmental Engineering, Incheon National University, Incheon 406-772, Korea; E-Mail: gyewoon@incheon.ac.kr

2 Department of Agricultural \& Rural Engineering, Chungbuk National University, Chungbuk 362-763, Korea; E-Mail: maeng@chungbuk.ac.kr

3 University Nice Sophia Antipolis, Polytech Nice-Sophia, Sophia-Antipolis 06903, France; E-Mail: Philippe.GOURBESVILLE@unice.fr

* Author to whom correspondence should be addressed; E-Mail: seongjune@paran.com; Tel.: +82-32-851-5731; Fax: +82-32-851-5730.

Academic Editor: Vincenzo Torretta

Received: 15 January 2015 / Accepted: 7 April 2015 / Published: 10 April 2015

\begin{abstract}
Many problems that are encountered in regards to water balance and resources management are related to challenges of economic development under limited resources and tough competition among various water uses. The development of major infrastructure like airports in remote areas that have limited water resources is becoming a common problem. In order to overcome these difficulties, water management has to articulate and combine several resources in order to respond to various demands while preserving the ecological quality of the environment. The paper discusses the interest in implementing the Smart Water Grid concept on Yeongjongdo Island, which is the location of Korea's main airport. This new concept is based on the connection of various water resources and their optimized management with new information technology solutions. The proposed system integrates water generated through rainfall, external water resources (i.e., metropolitan water distribution system), gray water and other types of alternative water resources. The paper analyses the feasibility of this approach and explores interest in the Smart Water Grid concept.
\end{abstract}

Keywords: smart water grid; water balance; water supply; water security; assessment; limited water resources; Yeongjongdo Island; competitive uses 


\section{Introduction}

As in many Asian countries, Korea is facing the challenge of achieving economic development with limited water resources. Superficial water resources that are closely linked to annual climatological conditions characterize the Korean peninsula. The Korean water resources' environment is rapidly changing with climate evolution. Rainfall patterns have changed during recent decades and have become more intense and concentrated [1-5]. Under these new conditions, rainfall over the central area is increasing whereas in the southern part it is decreasing [6]. This new situation, combined with economic development, has led to water problems such as water shortage and water distribution cutting off for some municipalities. Under such a difficult situation, tough competition has arisen for various water uses; industry, agriculture and domestic being the most preeminent uses. At the same time, the country requires the development of modern infrastructure such as highways and airports. During recent years, due to the limited availability of space, major infrastructure like the Songdo area [7] or the Saemangum project [8] in located in estuarine tidal flat areas of the west coast. In such new environments, which are densely populated and are associated with major services like airports, the competition for water is particularly high because no local resources are available to meet demand. The development of such major projects requires importing or producing water resources. Obviously, such an approach is associated with high costs that are closely linked to production techniques and to the necessary network infrastructure.

The new challenges created by these new environments mean call for the development and implementation of a new paradigm for water supply and treatment. The new development approach has to optimize the water production and distribution process with maximum efficiency. In such an approach, information and communication technologies (ICT) have a major role to play especially for monitoring actions that are requested at each step. At the same time, the production of water for new services has to be achieved in a global context where such new production will not impact other services and/or the natural environment. This approach is fully in line with the concept of Integrated Water Resources Management (IWRM) [9-12]. The IWRM concept aims to maximize the economic and social welfare in equitable terms without compromising the sustainability of vital ecosystems, including human ecosystems, by promoting the well-coordinated development and management of water resources. IWRM approaches involve applying knowledge from various disciplines as well as the insights from diverse stakeholders to devise and implement efficient, equitable and sustainable solutions to water and development problems. As such, IWRM is a comprehensive, participatory planning and implementation tool for managing and developing water resources in a way that balances social and economic needs, and that ensures the protection of ecosystems for future generations. In such an approach, ICT solutions can play a key role for implementing the concepts of IWRM and achieving the sustainable use of water. However, the use and implementation of ICT has to be done carefully by targeting the most demanding and relevant domains of the water cycle. In order to identify which and how ICT solutions can be implemented, it is necessary to look at the water cycle through an approach based on functional domains and business processes. This methodology allows considering each action involved in resource management and identifying the potential ICT needs [11,13-16].

The paper focuses on new concepts and associated methodologies that are required for assessing water demand in high development areas which have insufficient resources, and for achieving sustainable 
water uses. In such difficult environments, and under the pressure of economic development, the concept of Smart Water Grid appears as a major concept that may potentially integrate the various dimensions of the problem and provide a relevant operational approach. Obviously, the main concept is built around the possibility to mobilize various resources in order to answer to the demands and to optimize resources with ICT methods and tools that could be mobilized in monitoring and operating activities. This approach is related to the concept of hydroinformatics that introduced modeling and simulation systems to the water domain. After presenting the new concepts, the paper concentrates on the assessment methodology that is required for introducing the Smart Water Grid approach. The approach is then applied to the Yeongjongdo Island that is the location of the Seoul International airport-one of the largest logistic infrastructures in the world-and several new urban development areas. On this island, the local water resources are insufficient for satisfying demand and a water grid has to be implemented. The design of this water grid is based on a systematic assessment (Figure 1) of the various water uses that have to be conciliated on the island.

AS-IS

TO-BE

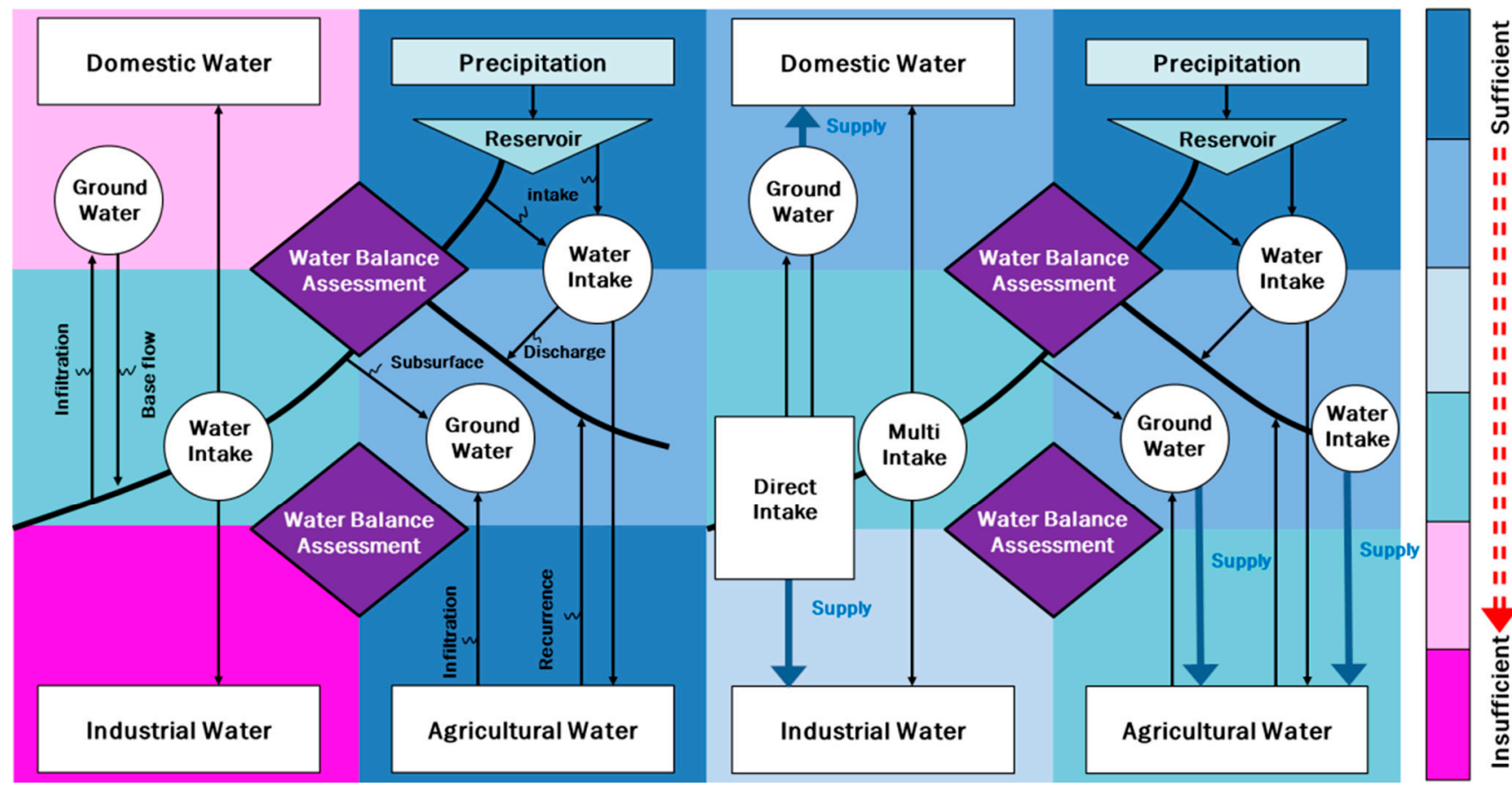

Figure 1. Water resources and associated uses assessment with improvement diagnostic.

\section{The Smart Water Grid Alternative}

The water distribution environment in urban areas is not exactly "grid" oriented, because the current system of water distribution is not broadly measured in real-time base usage and supply. Moreover, the current system focuses mainly on separating drinking water and non-drinking water. Without a large set of data collected through real-time measurement over the long term, it cannot be described as "grid" basis management. The concept of "grids" in water distribution can be defined when overall purposes of water usage in a region, such as drinking tap, gardening sprinkler, surface washing water, toilet flushing, industrial, recreational and agricultural water, are connected and integrated as data to manage [17]. The concept of "grids" in water management is summarized in Figure 2. 


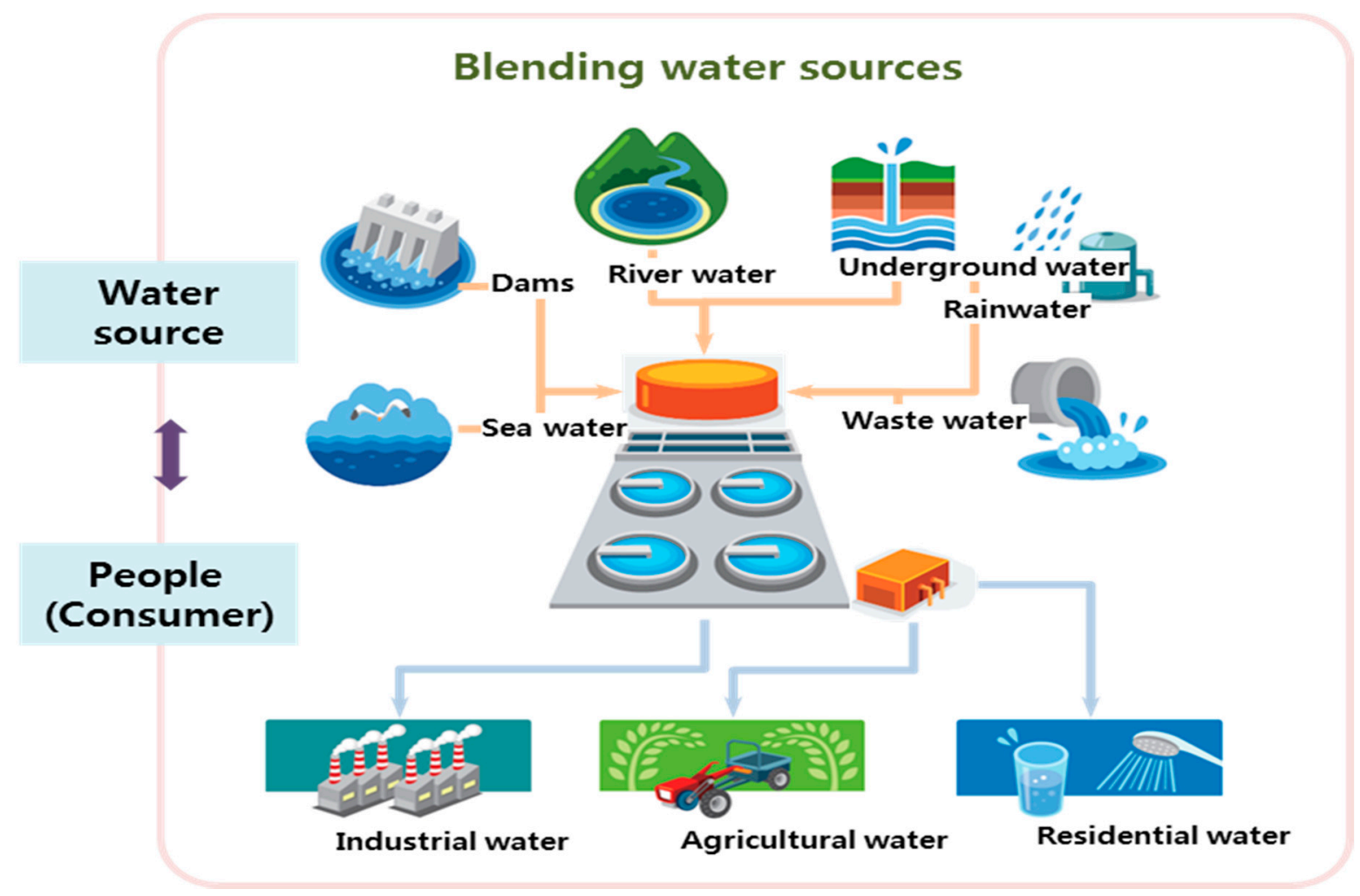

Figure 2. Conceptual diagram for smart water grid.

The Water Grid concept is a well-known approach that has been introduced gradually to water distribution networks in order to ensure capacity and increase security of customers. The basic idea is to use several resources that are interconnected to the network. The approach was promoted with the gradual extension of the networks and with the necessity to overcome the risk of failure. The use of a single resource has several risks such as the water supply distance and water quality. Therefore, this idea to combine different resources has gradually emerged. In the actual networks, the system has been improved with resources that combine fresh surface water (river water, lake water, etc.), groundwater and potable water produced from the sea through desalinization plants or even recycled waste water. At the same time, the diversification of the resources allows reducing the mobilisation of external resources which are located outside of the catchment and which are mobilized at high cost due to the need for network infrastructure [18].

The implementation and the management of the water grid requires efficient management - operation optimization mainly - that is much more complex than the traditional approach which is based only on a single resource point. The possibilities offered by information and communication technologies (ICT) and especially by the new generation of sensors combined with the communication network allow to monitor, in real time, the quality of the resources, to optimize the distribution operations and to ensure the security of consumers. The introduction of ICT solutions to the water domain represents an opportunity for both improving the management of the water grids and enlarging the mobilisation of various resources for a more sustainable management [19]. The concept of water grid is then enlarged to the smart water grid approach where ICT solutions have a key role to play [20] The concept of grid combined with usage of ICT for water management can define the new concept of "Smart Water 
Grid". The new approach could be used both to ensure security of water distribution and to increase reliability with a combination of several resources [21].

Climate change must be considered in relation to the activities and cycle above. Moreover, in the past, to make additional headspring, expanded facilities have mainly been utilized, and climate change was not considered. This study focused simply on the water supply system and unity water treatment system. Therefore, one integrated and effective water management with low-energy and high-efficiency is needed. The Smart Water Grid (SWG) can make use of local IT skills at a global level to solve this problem, which can lead to the generation of a green water industry.

To overcome the limitations of the existing water resources management system, the SWG was developed, which is an intelligent water management system, combined with the most up-to-date ICT. The SWG project is a technology development organization aimed at combining water business (water) with information business (smart) and infrastructure business (grid), and bridging the gap of water resources. The ultimate goal is to achieve water quality and water safety using low energy and with high-efficiency, while dealing with climate change. This relies on the following: technology assuring and distributing regional and temporal safe water resources that considers climate change; a water balance assessment and automation of water supply in the area (grid); technology for water supply assessment and management; two way (importing and exporting data) real time optimal operation technology; ensuring all essential technology is combined with ICT integrated water resources technology.

Furthermore, the applied technology must fare well with local conditions. In the near future, the SWG package will be applied as a micro unit (apartment complex, building, etc.) in developing countries.

Innovation in ICT is driven by uninterrupted progress in hardware performance for processing quantities, storing data and growing network capabilities, and wired and wireless technology. A recent example is the use of the sensor for determining physical, chemical and biological quantities, as well as qualities, that when integrated into communication and networking, opens the door to valuable insights on the Internet of Things [21]. The ability to interact with objects can be altered remotely based on the immediate or present needs, in accordance with the existing end-user agreements.

In this paper, the Smart Water Grid concept is implemented in an artificial environment which is used as support for a major infrastructure-airport - and where very limited water resources are available. Obviously, those resources can not cope with the demands, and a global strategy, optimized and based on multiple sources, has to be defined and implemented. This strategy starts from measuring and analyzing the data on water to check the water quantity and quality for assessing and securing water balance for each water use.

The first area of concern when applying a model is a general and very detailed procedure for producing a mandatory result. To meet the objectives of this study, the result must be a balance of water regardless of whether it is sufficient or not. Figure 3 presents the general framework of the modeling system. Table 1 lists the modules necessary to cover the integrated modeling framework described above. 


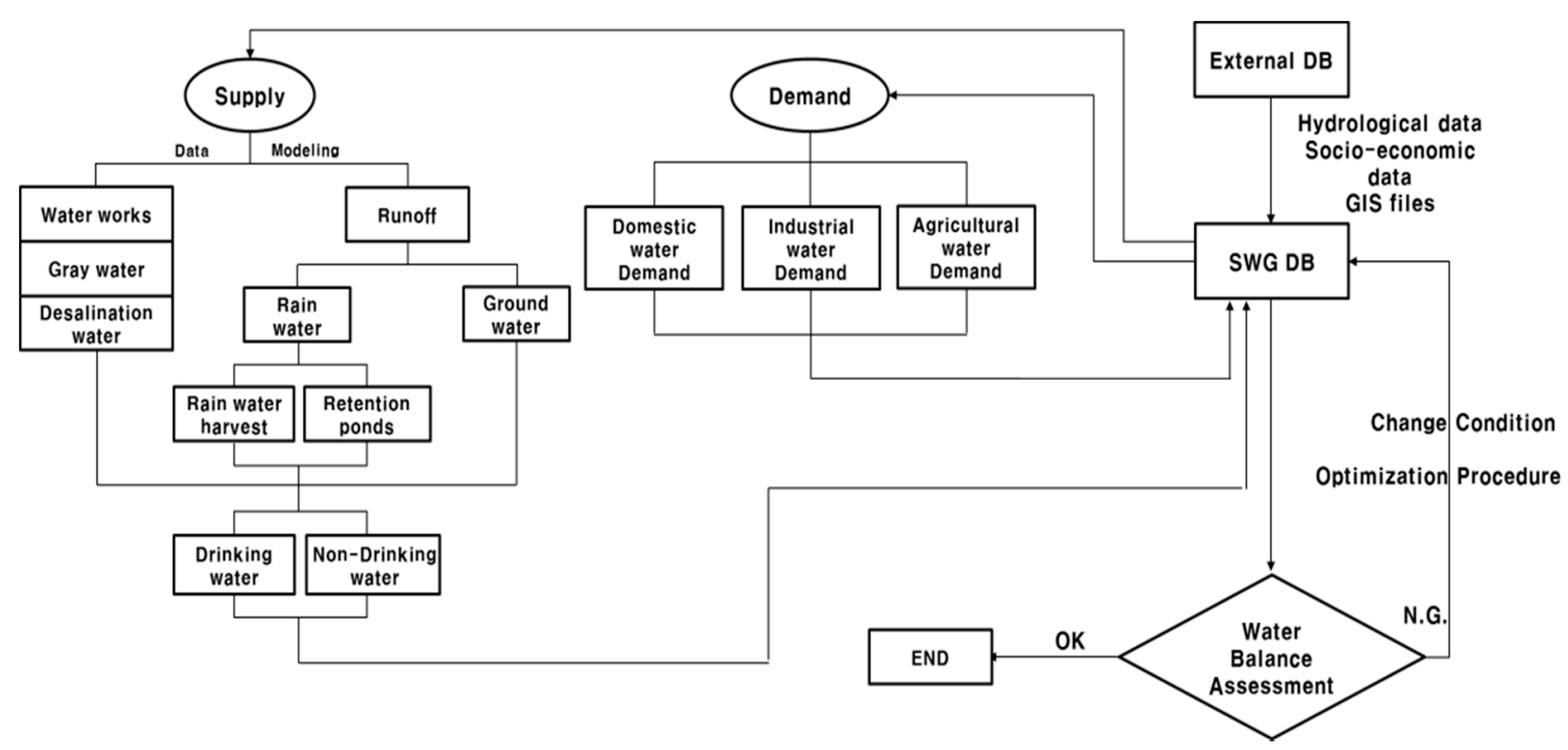

Figure 3. Overall framework of modeling for water balance assessment.

Table 1. Description of the necessary modules.

\begin{tabular}{ccc}
\hline Module & Named & Procedure \\
\hline GIS interface & SWG-PP & Providing basic interface, GIS pre-processing, Projection and transformation \\
Rainfall-runoff & SWG-Runoff & Climate data management, Rainfall-runoff modeling \\
Channel flow & SWG-UDS & Routing channel, Open channel flow modeling(Sewer and river) \\
Water demand & SWG-Demand & Prediction of water demand(According to the scenario) \\
Water balance & SWG-WB & Water budget analysis, Predicting and quantifying water shortage \\
\hline
\end{tabular}

This system basically provides a water balance with the total water resources available and the total water demand. This is purely a quantity wise water balance that can occasionally provide the state of the water balance as sufficient, regardless of the water use, that needs to secure a sufficient water quality, such as drinking water. Therefore, the quantity of each water resource produced from modeling or user specification is available to be chosen to meet demand for different purposes of water use. For example, ground water, desalinated sea water and stream water can be used for all water uses but, collected rain water at the retention pond, treated waste water and gray water can be used only for agricultural purposes and partially for industrial activities unless the water is used as a material of a food product. On the other hand, the description from the example above is not always the truth but the above may be generally assumed because water quality of sources is always varying and it occasionally depends on the water treatment method. In addition, there is another issue regarding the quantity of water from the source. Sometimes, a source in the domain can supply very little water and requires a huge pipe line and treatment facility, which can often be the case. Moreover, the source may be excluded from the selection unless it is the only source to take water from. Therefore, this module allows the users to specify each source that is used and the purpose of water use.

The fundamental concept of smart water management systems starts with a global water balance assessment by making a comparison between water resources available and predicted water demand. This mainly uses calculated values through modeling and monitoring, however, the data from additional water resources such as collected rainwater, groundwater and water produced through 
desalinization and purification processes (in case of reuse of waste waters) should be collected separately. The basic equation to preserve the water balance can be performed as Equation (1);

$$
\mathrm{W}_{\mathrm{B}}=\mathrm{W}_{\mathrm{A}}-\mathrm{W}_{\mathrm{D}}
$$

where

$\mathrm{W}_{\mathrm{B}}\left(\mathrm{m}^{3}\right)$ is a water balance that shows if the water supply system is alright;

$\mathrm{W}_{\mathrm{A}}\left(\mathrm{m}^{3}\right)$ is water resources available in the study area;

$\mathrm{W}_{\mathrm{D}}\left(\mathrm{m}^{3}\right)$ is water demand in the region.

$\mathrm{W}_{\mathrm{A}}$ can be calculated through Equation (2);

$$
\mathrm{W}_{\mathrm{A}}=\mathrm{W}_{\mathrm{E}}+\mathrm{W}_{\mathrm{O}}+\mathrm{W}_{\mathrm{M}}
$$

where

$\mathrm{W}_{\mathrm{E}}\left(\mathrm{m}^{3}\right)$ is an emergency water stored in the water supply reservoir,

$\mathrm{W}_{\mathrm{O}}\left(\mathrm{m}^{3}\right)$ is the water officially distributed, and can become zero if there is an emergency status;

$\mathrm{W}_{\mathrm{M}}\left(\mathrm{m}^{3}\right)$ is water resource available through smart water treatment plant that can supply non-drinking water if it is not an emergency stage.

\section{Strategy for Smart Water Grid Implementation}

Water supply in an area with limited resources, such as an island, starts from the water intake station. The water intake station is managed by law or regulation for public health to conserve the quantity and quality of water. The water from the intake station is treated through the water purification plant with the quality of drinking water. It is a simple water utilization in which water is supplied to the consumers and goes to waste water treatment plant after usage. However, the water will be treated as drinking water at the water purification plant which mainly is located outside the region. It is occasionally coming through the unique pipeline installed by the official water distributor. This situation is obviously at risk because there is no alternative water for emergency state of water supply system. The basic system for water supply in a typical area can be illustrated as Figure 4.
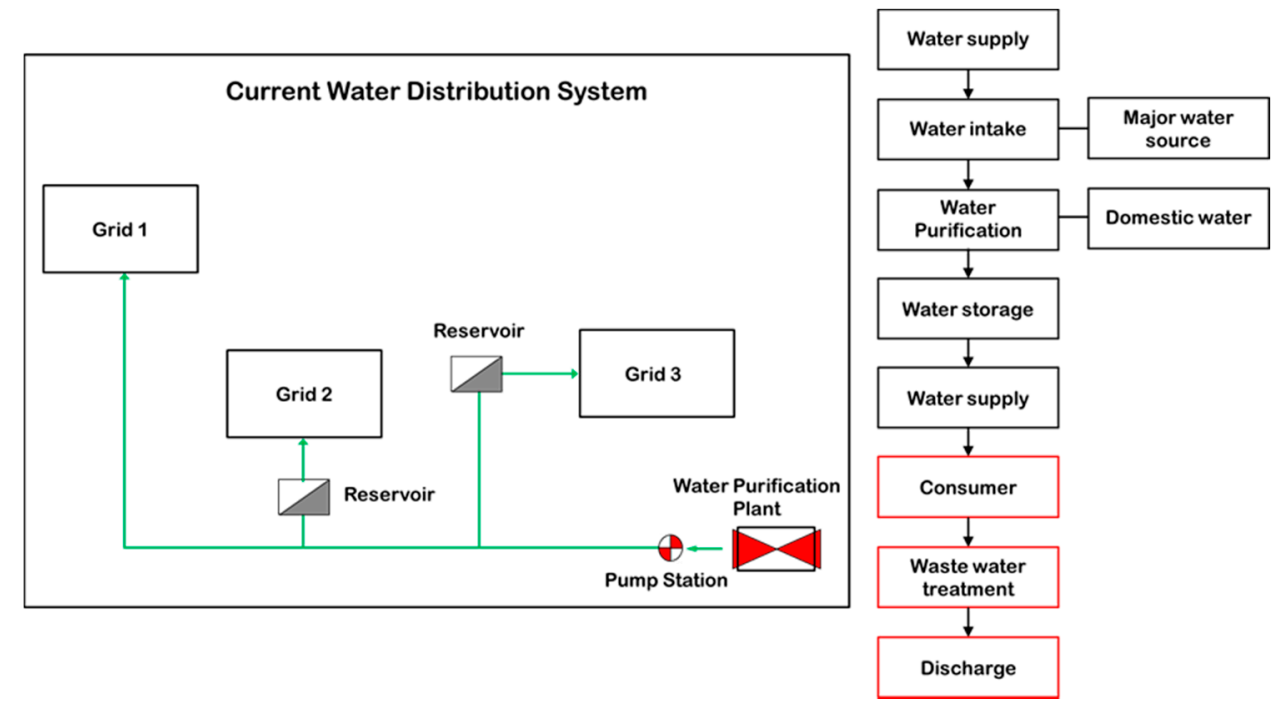

Figure 4. Basic diagram of water supply system. 
Mainly, the water from the water distribution system is supplied to the target grid by storing it in the water storage reservoir and each grid should have its own reservoir to make the water supply more stable, as shown in Figure 5. Water storage reservoirs have their own capacity to buffer the water cutting off problem and they must cover the water supply for 6-24 h at an emergency state, without any external water supply.

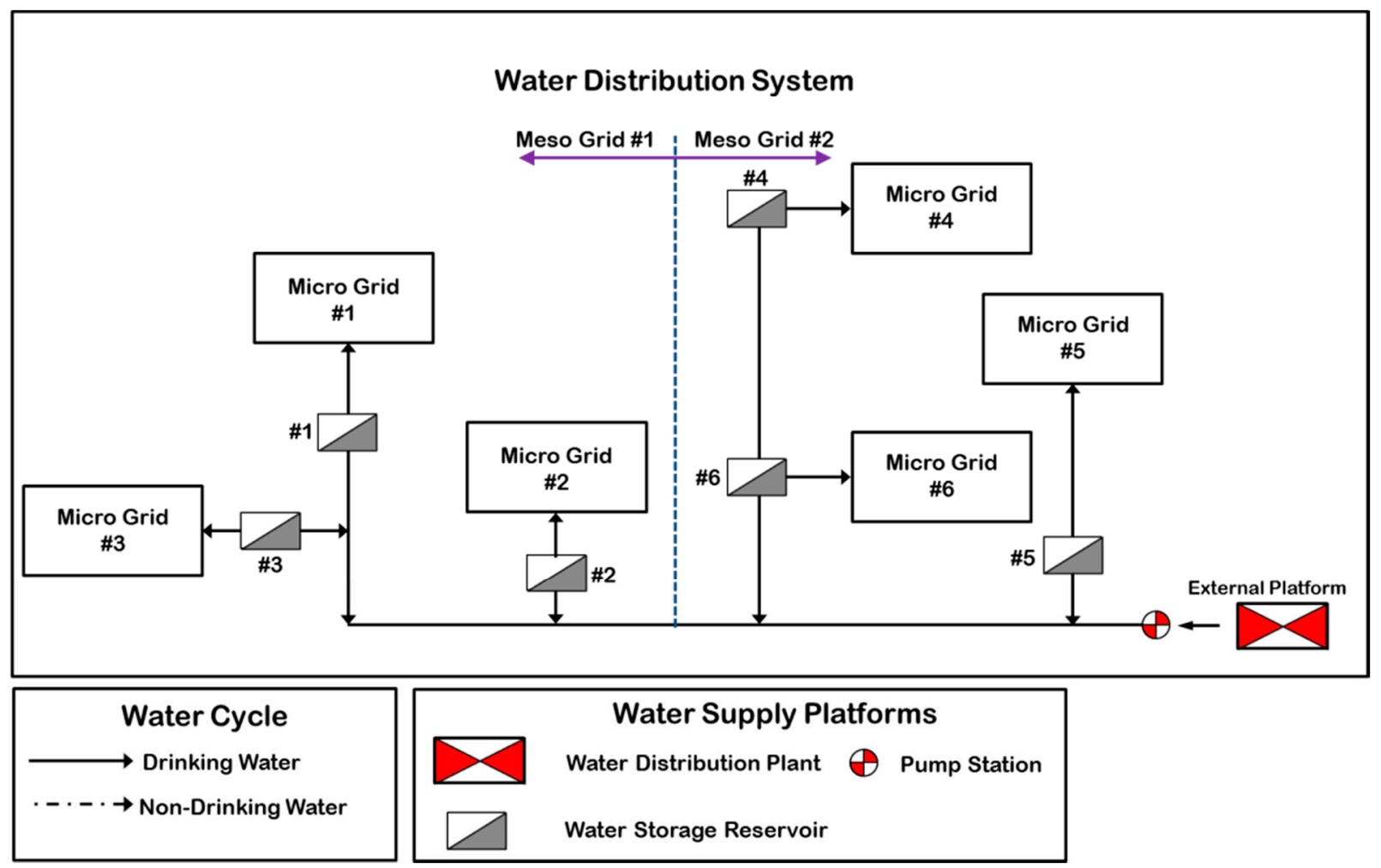

Figure 5. Water storage facilities for water supply.

The water purification plant provides water with the right quality level for drinking use. However, the purpose of water use is not just limited to drinking water, because consumers prefer to use purified water also for all domestic and commercial uses such as gardening, washing, toilet flushing and so on, as summarized in Table 2 [22].

Table 2. Mean daily water use for different purposes for domestic water [22].

\begin{tabular}{|c|c|c|c|c|c|c|}
\hline \multicolumn{2}{|c|}{ Purpose } & $\begin{array}{c}\text { Consumption } \\
\text { (L/cap/day) }\end{array}$ & $\begin{array}{c}\text { Proportion } \\
(\%)\end{array}$ & $\begin{array}{c}\text { Priority } \\
\text { Level }\end{array}$ & $\begin{array}{c}\text { Absorption } \\
\text { of Human }\end{array}$ & Remarks \\
\hline \multirow{3}{*}{ Drinking } & Drinking & 1.4 & 0.8 & Very High & Very High & \\
\hline & Cooking & 25.0 & 14.2 & Very High & Very High & \\
\hline & Sub-total & 26.4 & 15.0 & - & & \\
\hline \multirow{5}{*}{ Nondrinking } & Washing & 98.8 & 56.1 & Middle & Middle & Laundry, Dishes \\
\hline & Bathing & 37.5 & 21.3 & High & High & Shower, face, teeth \\
\hline & Toilet & 10.4 & 5.9 & High & Low & \\
\hline & Gardening & 3.0 & 1.7 & Low & Low & \\
\hline & Sub-total & 149.7 & 85.0 & - & & \\
\hline \multicolumn{2}{|c|}{ Total } & 176.1 & 100.0 & - & & \\
\hline
\end{tabular}


As shown in Table 2, the proportion of drinking water use in total domestic water demand is only $15 \%$. Therefore, a water storage reservoir can supply drinking water for more days if it is possible to secure alternative water resources for non-drinking purposes. By separating water supply, the water distribution system with limited water resources can be re-illustrated as Figure 6 for emergency state. In an ordinary state of affairs, alternative water resources, such as rain water stored in retention ponds, stream and ground water, supply non-drinking water for agricultural usage, public gardening and public washing. The official water distribution system supplies domestic water as usual. However, if an accident occurs in the water distribution system's area, the water storage reservoir stops the water supply through valves and the alternative water resources treated a through simple water treatment plant will start providing non-drinking purpose domestic water with the consumer's approval. The drinking water must be provided through a restricted water supply way, such as bottle delivery or operating water wagons.

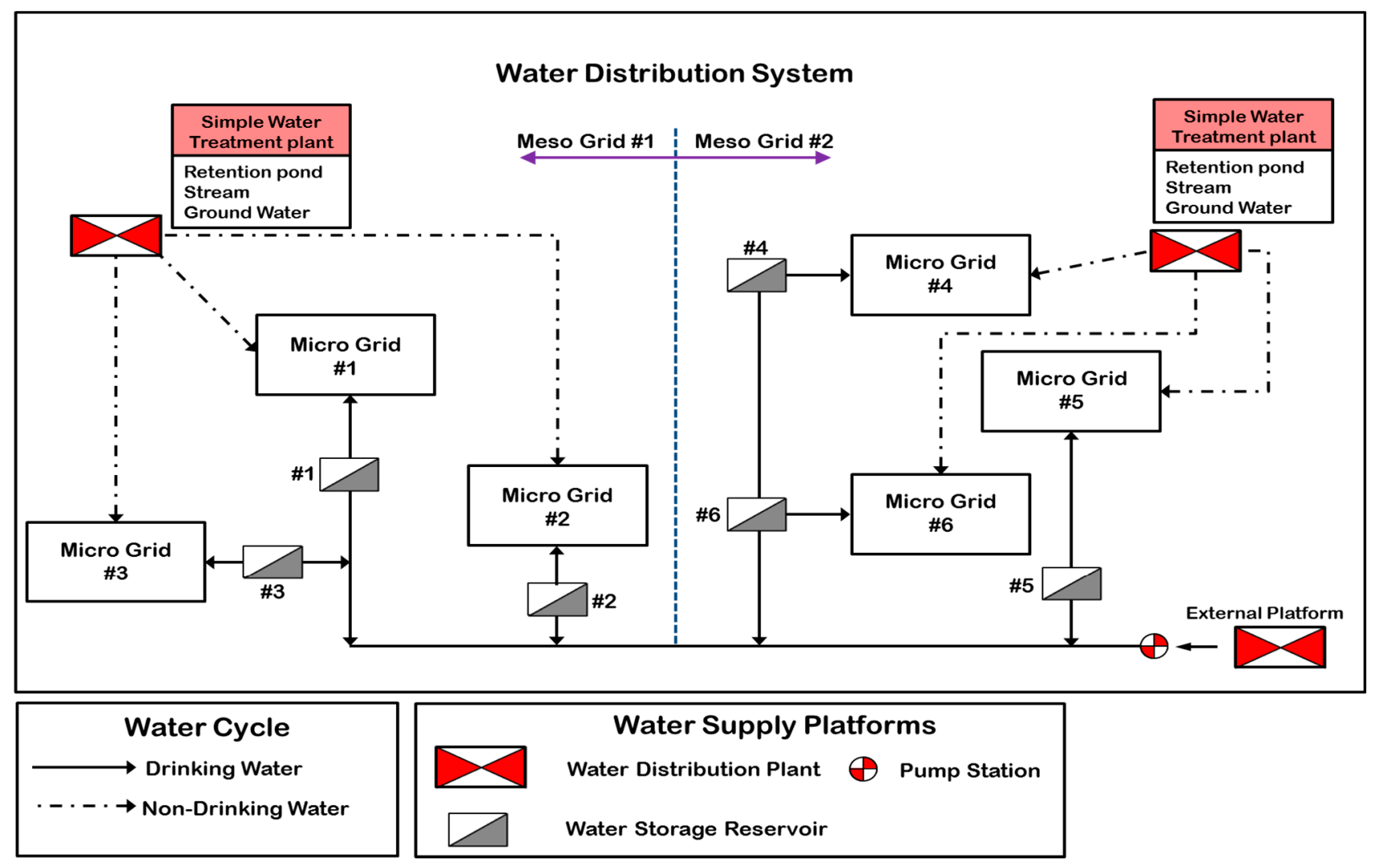

Figure 6. Improved system of water distribution.

The best way for emergency water distribution is to secure water treatment plants which can produce drinking quality water. However, it is difficult and costly to establish a facility to produce drinking water, unless a well-managed water intake station is secured. The improvement concept can be re-illustrated as a water loop which must be more efficient in supplying water, as shown in Figure 7. In this water loop concept, without installing additional pipe line, ordinary water supply and alternative water resources can share the facility to achieve the fastest reaction to accidents. 


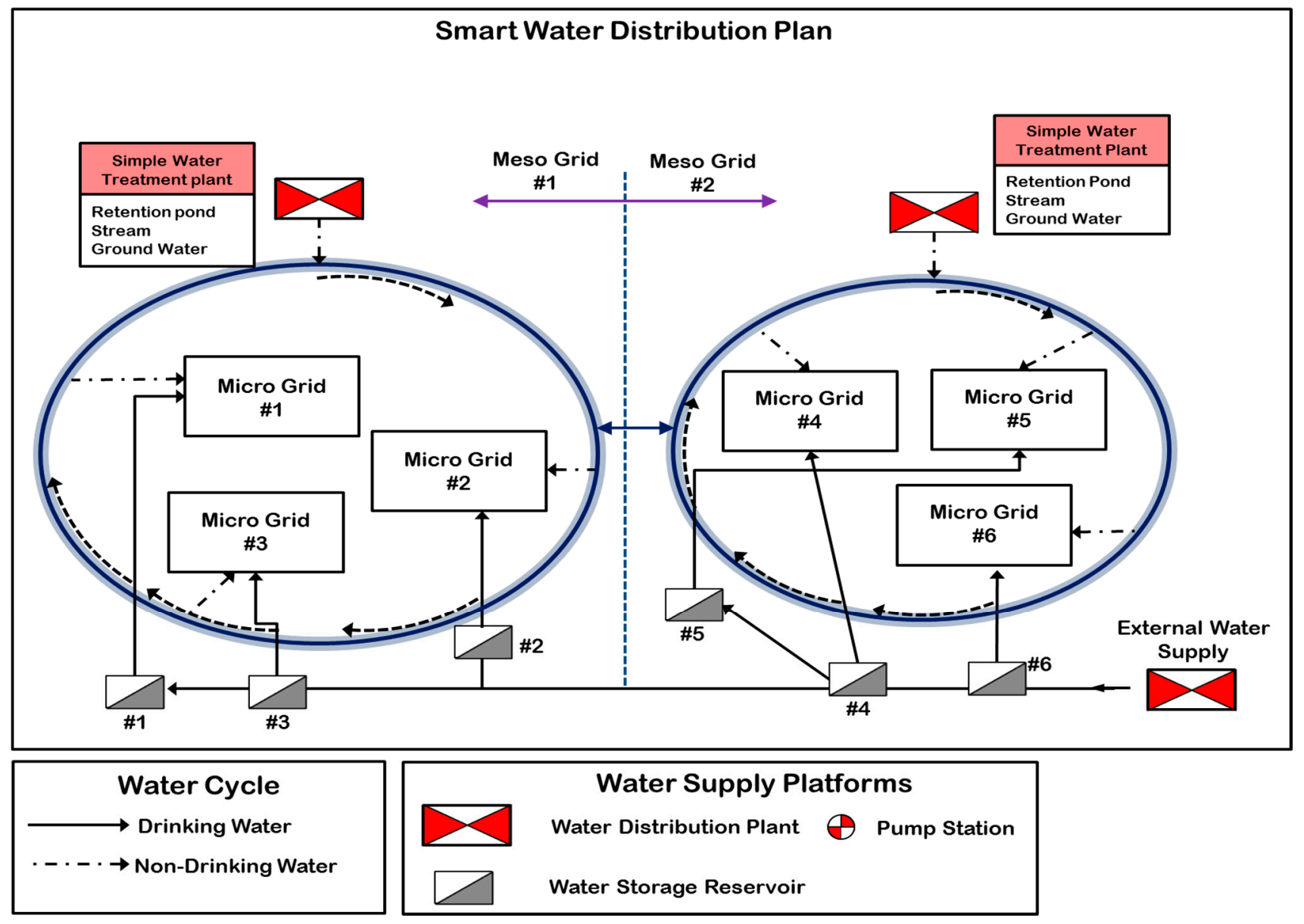

Figure 7. Improved system of water distribution with the water loop concept.

This improved system proposed above is complicated comparing to the current system. Thus, it is necessary to make a control system to monitor the states of water and to make an action plan. The current system as shown in Figure 5 is not sufficient. This study developed a system for improved water distribution system control.

If the value of $\mathrm{W}_{\mathrm{B}}$ in Equation (1) is more than zero as ordinary state of water supply, the system shows only a general state of water cycle in the target area and this general procedure in the ordinary water supply system is illustrated in Figure 8. The concept of water distribution is basically the same as the current system, but the control system is added and the use of alternative water resources is included.

However, if the value of $W_{B}$ in Equation (1) is less than zero by cutting off water supply because of accident or drought, it is an emergency state and it is necessary to secure water to further supply it to customers. The system shows the emergency warning message at the place in distress and the general procedure should be changed for the emergency water management mode illustrated in the Figure 8 with abnormal state detection. As the concept described above shows, the drinking water can be supplied through the water storage reservoir and the alternative water resource can only supply non-drinking purpose domestic water unless the water treatment facility to produce drinking water is prepared. The smart water treatment plant is simply producing non-drinking purpose water through minimized water treatment procedures. The system tries to send messages to the consumers to inform them about the non-drinking purpose water supply. 


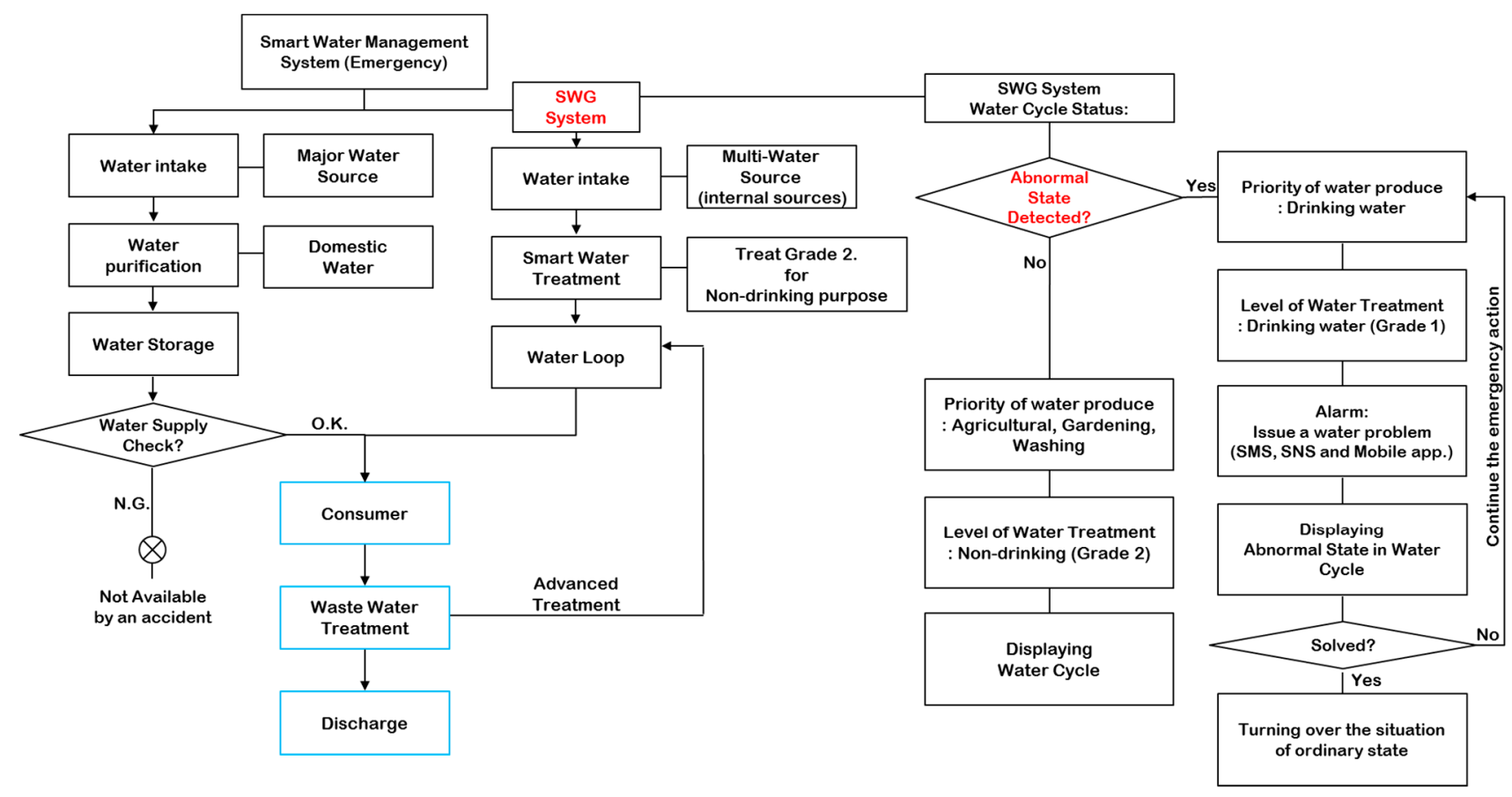

Figure 8. Ordinary water distribution with smart water technologies.

\section{Application to Yeongjongdo Island}

Incheon International Airport (IIA) is the largest airport in South Korea, the primary facility serving the Seoul Capital Area, and one of the largest and busiest airports in the world. For nine years in a row (2005-present), it was rated the best airport worldwide by Airports Council International. Located $48 \mathrm{~km}$ west of Seoul, the capital and the largest city of South Korea, IIA is the main hub for the major Korean airline companies and serves as a hub for international civilian air transportation and cargo traffic in East Asia. The IIA is also currently Asia's eighth busiest hub in terms of passengers, the world's fourth busiest facility for cargo traffic, and in 2013 was the world's ninth busiest airport in terms of international passengers with more than 40 million international passengers. The IIA is located on Yeongjongdo Island as shown in Figure 9.

Incheon International Airport is located west of Incheon's city center, on an artificially created piece of land between Yeongjong and Yongyu islands. The two islands were originally separated by shallow sea. That area between the two islands was reclaimed for the construction project, effectively connecting the once separated Yeongjong and Yongyu islands. It is connected to the mainland by major infrastructure like expressways and bridges. With the completion of phase 2 of the development project, the airport will have an annual capacity of 410,000 flights, 44,000,000 passengers, and nearly 4,500,000 metric tons of cargo. A new development phase will start in 2017 and will engage the final phase up to 2020. Upon completion, the airport will have two passenger terminals, four satellite concourses, 128 gates, and five parallel runways (one exclusively for cargo flights). It will be able to handle 100 million passengers and 7 million metric tonnes of cargo annually, with further possible expansions. The airport is projected to be transformed into one of the top 10 busiest in the world by 2020 . Associated to the airport development, several large new towns are under construction or under inception phase. Those new urban developments will significantly increase the population living on the island. 


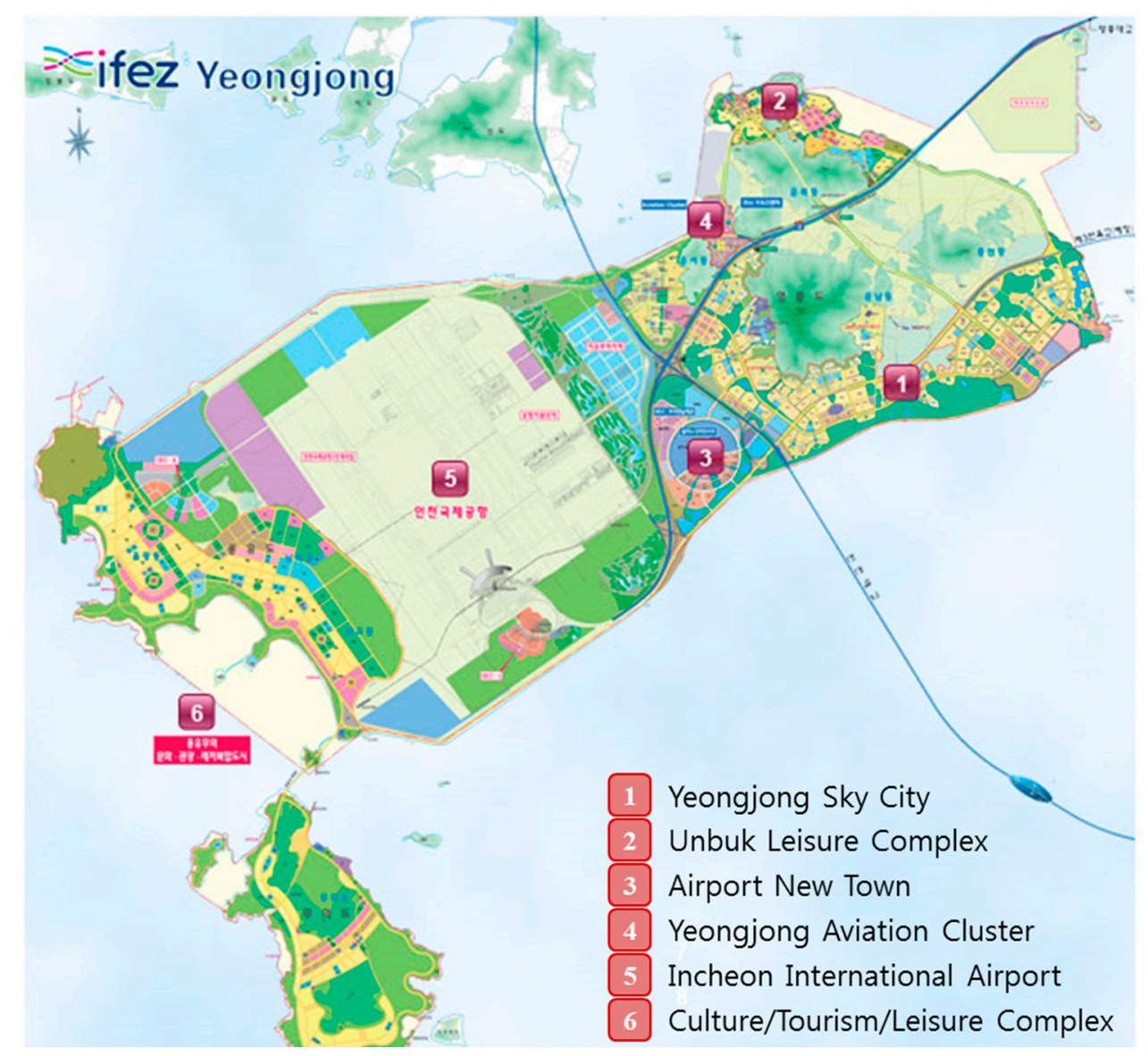

Figure 9. The Yeongjongdo Island with airport and coast line [23].

Obviously, local water resources cannot cover the demands of the airport and of the new urban environments. For the time being, fresh water is coming from the water purification plant located in Incheon city and is reaching the island by pipes. There are actually currently no challenges in the water supply system. However, the designed systems present some potential risks of failure under specific situations. Large proportions of water resources in Korea rely on river fresh water. In the Youngjongdo Island, tap water is provided by the water purification plant which is directly pumping water from the Han River. The water supply system for the island is based on this unique resource without any alternative option that may be required in case of equipment failure, drought or accidental pollution. Therefore, if an accident occurs at the main water pipe in the sea, no other water alternative is available on this island, as shown in the Figure 10.

On Yeongjongdo Island, the current population is 52,300 and the total area, including reclaimed land, is $116 \mathrm{~km}^{2}$. From the total of $116.77 \mathrm{~km}^{2}, 14.9 \mathrm{~km}^{2}$ is dedicated to agriculture, $35.9 \mathrm{~km}^{2}$ to forest, $2.6 \mathrm{~km}^{2}$ to parks, $0.7 \mathrm{~km}^{2}$ to industrial zone, $7.4 \mathrm{~km}^{2}$ to residential area and $15.3 \mathrm{~km}^{2}$ to public space and other purposes [24]. The annual rainfall is $1412 \mathrm{~mm}$, annual average air temperature is $12.5^{\circ} \mathrm{C}$ and the number of annual average rainy days is 115 days [25].

The chosen scenario is an accident at the water pipe coming across the sea. This scenario can be assumed easily and it is simple, however it can be a huge problem since the sub marine pipeline is the only way to transport drinking water for the island itself and the airport. The pipe is $2.3 \mathrm{~km}$ long and its current capacity is $155,000 \mathrm{~m}^{3} /$ day. 


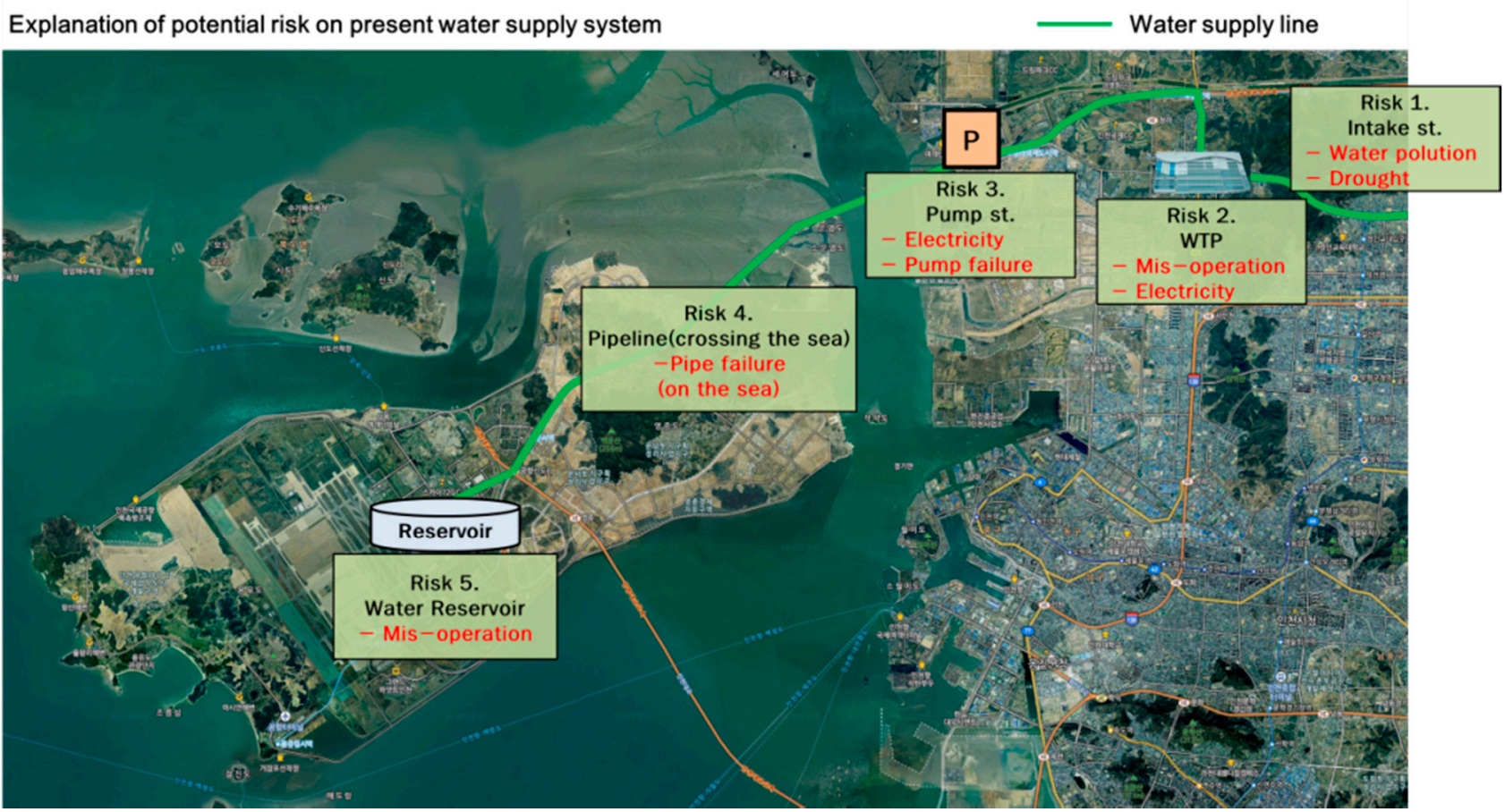

Figure 10. Potential risks to present water supply system of the Youngjongdo Island.

For the application of the suggested approach, the island is divided into two different zones that correspond to two water grids as presented in Figure 11. The alternative water resources to be considered in this study are also illustrated in Figure 11. The first grid is located on the eastern part of the island. This grid includes Yeongjong district which used to be a traditional island before the reclamation projects, Yeongjong Sky City, Unbuk new town and Airport new town. The second grid is the western part of the island including the Incheon International Airport Yongyu district and Muui district.

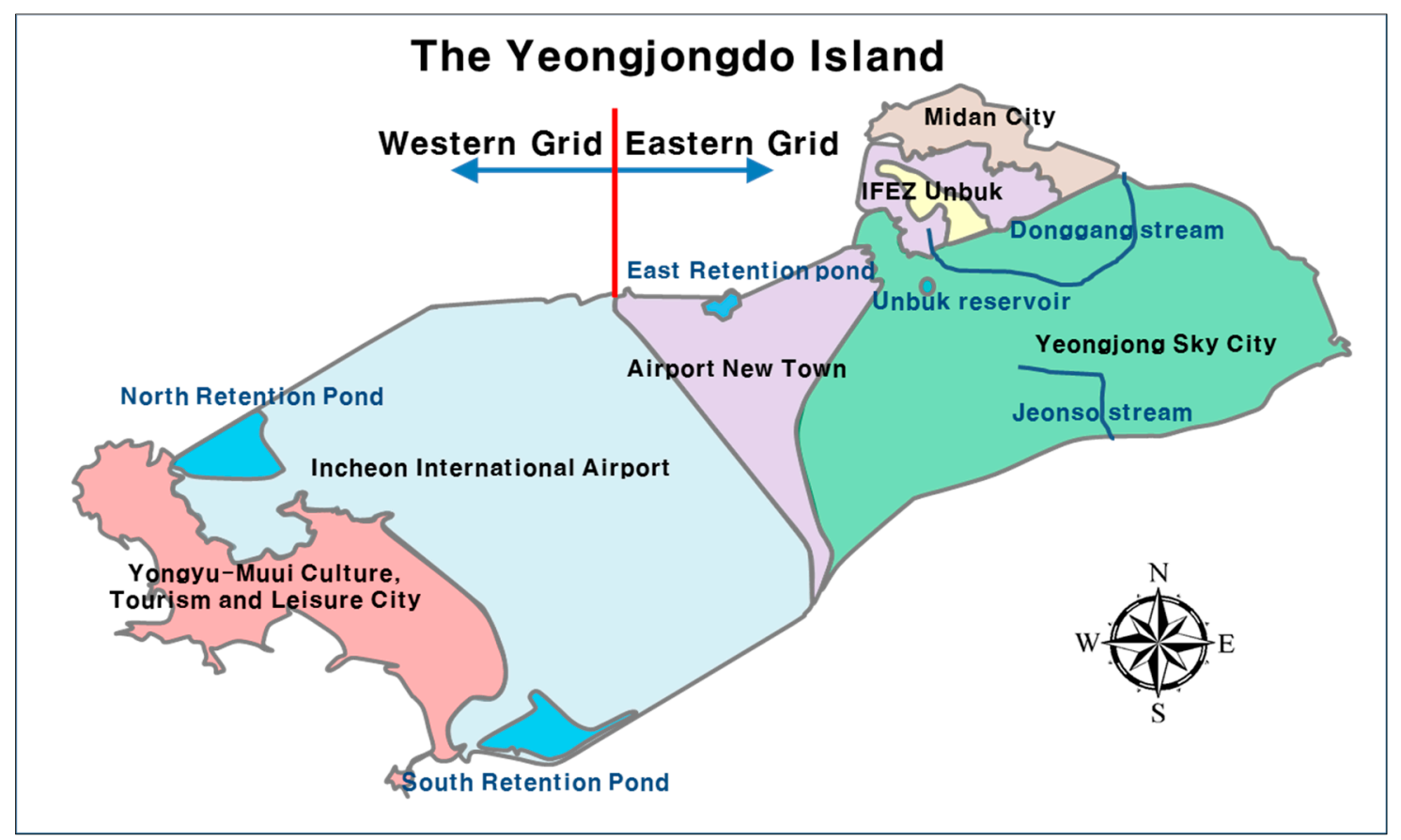

Figure 11. Division map of western and eastern grid. 
There are six reservoirs under operation or planned under the on-going developments. However, these reservoirs under planning or construction will be completed in the target year (i.e., year 2025). Ground water and gray water are being used as minor water resources.

The analysis includes wastewater treatment plants planned and under construction. Therefore, if an accident occurs, the water resources available can be summarized as described in Table 3.

Table 3. Water available at each grid (unit: $\mathrm{m}^{3}$ ).

\begin{tabular}{cccc}
\hline Water Type & Eastern Grid & Western Grid (incl. Airport) & Remarks \\
\hline $\begin{array}{c}\text { Water stored at } \\
\text { the reservoirs }\end{array}$ & 66,000 & 54,000 & $\begin{array}{c}\text { Assuming the } \\
\text { maximum capacity }\end{array}$ \\
\hline Ground water & 12,135 & 2770 & Daily availability \\
\hline Gray water & 82,800 & 38,200 & \\
\hline Total & 160,935 & 94,970 & \\
\hline
\end{tabular}

However, if there is no facility for water treatment and distribution, ground water and gray water can only be supplied for a very limited area. In such case, the only available water corresponds to the volume stored in the reservoir. Although the accident occurred, the water demand for the area cannot be easily reduced unless the number of water consumers drops significantly. Therefore, water consumption at each grid can be described as shown in Table 4.

Table 4. Water demand at each grids (unit: $\mathrm{m}^{3} /$ day).

\begin{tabular}{cccccc}
\hline Grid & Domestic & Industrial & Agricultural & Others (Non-Drinking) & Total \\
\hline Eastern & 70,100 & 3500 & 20,110 & 2452 & 96,162 \\
Western & 52,800 & - & 8140 & 1543 & 62,483 \\
Total & 122,900 & 3500 & 28,250 & 4085 & 158,645 \\
\hline
\end{tabular}

The first priority is, obviously, to provide drinking water. The agricultural water demand can be met with non-drinking water under specific conditions and awareness procedures. Even if the drinking water is the main priority, the stored resources are not sufficient to provide a full day consumption. In such situation, multi water sources have to be considered.

\section{Results and Discussion}

This study demonstrates that the water distribution was improved through the concept of "Smart Water Grid" applied on an island area with limited water resources. Alternative water resources data from modeling work and data collection is applied for this case study. This section shows the results from the demonstration of "Smart Water Grid" implementation in terms of securing water resources similarly to the IWRM case in a compact region and discusses using this concept in the real world and suggests further studying it in different research fields.

The first step of the demonstration is a water balance evaluation. Data sets on water resources and demand analyzed in the section above are used for the implementation. The multiple water resources from the Yeongjongdo Island as study area are analyzed at different spots such as:

- A reservoir and three retention ponds which are able act as both water source and water storage; 
- Two streams which flow to the sea and that may provide resources only after intense rainfall events. The volumes of the streams cannot be used without additional storage facilities.

Water sources of the eastern grid were analyzed at four different areas, such as a reservoir and a retention pond, which can be both a water source and water storage, and two streams that flow to the sea and are available only when intensive precipitation occurs. Therefore, it is basically impossible to use the water from streams without an additional storage facility. In addition, it is also necessary to consider the possibility of using the Unbuk reservoir because the quantity of water resource is small compared to other sources.

Basically, the maximum quantity of each water source can be estimated by the accumulated water volume. If it is possible to keep the water through infinite storage, the total quantity of water from local sources can be more than enough to cover the total water demand, as shown in the simple water balance assessment summarized in Table 5 .

Table 5. Water balance at eastern grid in the Yeongjongdo Island.

\begin{tabular}{|c|c|c|c|}
\hline Item & $\begin{array}{c}\text { Yearly Maximum Volume of } \\
\text { Water(A) }\left(1000 \mathrm{~m}^{3}\right)\end{array}$ & $\begin{array}{c}\text { Daily Availability(A/365) } \\
\left(1000 \mathrm{~m}^{3}\right)\end{array}$ & Remarks \\
\hline Donggang Stream & 13,160 & 36.1 & \\
\hline Jeonso Stream & 6183 & 16.9 & \\
\hline Unbuk Reservoir & 837 & 2.3 & \\
\hline East Retention Pond & 39,259 & 107.6 & \\
\hline Ground Water & 4417 & 12.1 & \\
\hline Total & 63,856 & 175 & \\
\hline Water Demand & 35,099 & 96.2 & Including agricultural water \\
\hline Water Balance & 28,757 & 78.8 & (Total Water-Water Demand) \\
\hline
\end{tabular}

Water sources of the western grid are analyzed at two different spots as two retention ponds which are able to act as both a water source and water storage. However, there is one more matter to be considered in regards to these retention ponds, which are pretty close from the airport, because the major purpose of the retention pond is to prevent flood disaster at the airport, a very important infrastructure under national protection. Also, those spots cannot store much water because of the birds which are harmful for airplanes and will come if there is water and fish. Therefore, it can never be fully stored and those matters should also be considered.

Similarly, in the eastern grid, the maximum quantity of each water source can be estimated by the accumulated water volume. If it is possible to keep the water through infinite storage, the total quantity of water from local sources would be more than enough to cover the total water demand as determined through a simple water balance assessment which is summarized in Table 6. 
Table 6. Water balance at western grid in the Yeongjongdo Island

\begin{tabular}{|c|c|c|c|}
\hline Item & $\begin{array}{l}\text { Yearly Maximum Volume } \\
\text { of Water (A) }\left(1000 \mathbf{~ m}^{3}\right)\end{array}$ & $\begin{array}{l}\text { Daily Availability } \\
(\mathrm{A} / \mathbf{3 6 5})\left(\mathbf{1 0 0 0} \mathbf{~ m}^{3}\right)\end{array}$ & Remarks \\
\hline North Retention Pond & 55,247 & 151.4 & \\
\hline South Retention Pond & 51,398 & 140.8 & \\
\hline Ground Water & 1011 & 2.8 & \\
\hline Total & 107,656 & 295 & \\
\hline Water Demand & 22,806 & 62.5 & $\begin{array}{c}\text { Including } \\
\text { agricultural water }\end{array}$ \\
\hline Water Balance & 84,850 & 232.5 & $\begin{array}{c}\text { (Total Water-Water } \\
\text { Demand) }\end{array}$ \\
\hline
\end{tabular}

However, as describing the characteristics of water sources, the water is basically flowing into the sea and there must be additional facility to store and to treat water sources. The suggestion of this study is to apply the smart water loop to secure emergency water which can be distributed if the water from external water purification plant cannot be inflowed in the study area. It addition, this system should also include the smart water treatment plant to maximize use of internal water resources according to a variety of water purposes. Water consumption spots would share the water reservoirs for optimal distribution for drinking water. Additionally, the smart water treatment plant producea water and blenda the produced water appropriately into reservoirs in emergency states for non-drinking domestic water. The blended water can be supplied to the consumers through the water loop system. Figure 12 shows the concept of smart water distribution plan suggested in this study.
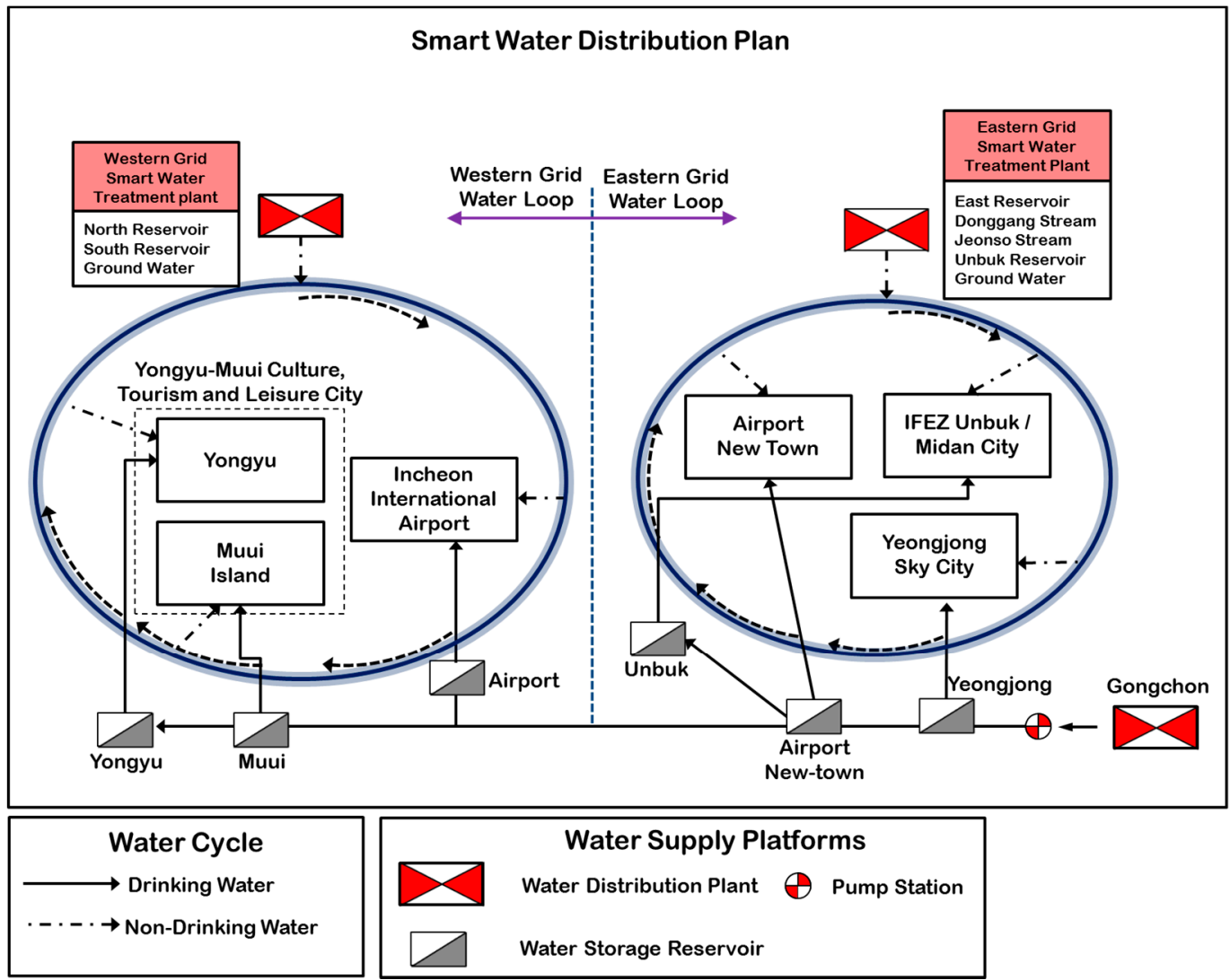

Figure 12. Improvement of water distribution plan. 
This scenario considers the water supply during an emergency state with only a minimized water treatment for non-drinking purposes from multi water sources in the study area. Two water loops at the east and west are considered to be connected to the current water distribution system and the highest priority for water supply is the water supply to the airport, to maintain the function of this important infrastructure.

Therefore, if the accident can be fixed within a few days, a restricted water supply is not applied to the airport. On the other hand, if the emergency state is for a longer time, drinking water should be provided at drinking fountains installed at several places in the airport. The domestic water demand has been calculated to be $12,918 \mathrm{~m}^{3} /$ day and the water demand for the airport has been determined to be $27,700 \mathrm{~m}^{3} /$ day. According to a previous study, only $15 \%$ of domestic water is used for drinking and cooking purposes. Therefore, it is possible to assume the amount of daily domestic water to be provided as drinking water quality is $1938 \mathrm{~m}^{3} /$ day. In addition, half of the airport water demand is occasionally provided through an internal water treatment plant installed in the airport as gray water supply; hence, the necessary quantity of airport water supply for drinking water was determined to be $13,800 \mathrm{~m}^{3} /$ day. Therefore, the total drinking water demand with the consideration of fully supplying the airport water demand and a restricted water supply for domestic water as supplying only drinking water could be determined to be $15,738 \mathrm{~m}^{3} /$ day.

The quantity of drinking water stored in the water storage reservoir in the whole island is $120,000 \mathrm{~m}^{3}$. Therefore, if the action plan described in Figure 8 can be properly arranged, the maximum days to supply drinking water without an external water supply in Yeongjongdo Island is 7.6 days. Therefore, it is necessary to provide additional plans, such as the operation of water wagons and water bottle services if a longer period is needed to fix the water supply interrupted by accident or short-term drought.

In terms of water quality, multiple water sources in the Yeongjongdo Island show the value of BOD less than $5.2 \mathrm{mg} / \mathrm{L}$ at the north reservoir and much less at the others. Thus, it is appropriate to be used as non-drinking water such as agricultural water, gardening and surface wash off. Therefore, treated water in the water storage reservoir can be used for drinking purposes and maintaining the proper functioning of the international airport.

This system was suggested without considering the additional water treatment plant; however, the best solution is installing additional water treatment plants with minimum investment of budget. Therefore, it is necessary to continue this study further exploring water quality and water treatment technology.

\section{Conclusions}

This study developed an improvement on urban water cycles, especially for areas with limited water resources, such as an island region, through new water management technologies and a water balance assessment model. This study was carried out through several scenarios with future estimations for the Yeongjongdo Island and the following conclusions were made:

(1) This paper discussed "Smart Water Grid" technology to improve the water cycle in urban areas, especially regions with limited water resources, such as islands, integrated with information communication technologies (ICT) for water management. This study focused on a water distribution system to achieve more stable sustainable water distribution. The approach of "Smart Water Grid" helps handling the overall water cycle. 
(2) In terms of the "grid" of water management, it is necessary to consider the general water distribution system while balancing the potential water use purposes in the region. Thus, this study tried to connect simple modules to calculate and manage the water sources to include the water in the water cycle as an alternative water resource. The "grid" water management with "Smart Water Grid" drives the water cycle with an optimal use of combined resources and to be operational everywhere.

(3) An improved water supply system with minimum changes to the existing system is suggested as a type of water loop. Although the system is simply connected among the water supply facilities, such as reservoirs, streams and treatment plants, it can be powerful in terms of water supply if operation with ICT based system can be secured. Moreover, this system can be more efficient if it is applied in a new town with new supply systems, with SWG implementation from the planning phase.

(4) This study developed and applied a scenario for a water shortage problem at the real area to demonstrate that this system can be effective for water cycle improvement. Thus, the Yeongjongdo Island, where the international airport is located, is selected as the target area and this study assessed the water balance considering different scenarios and suggested a smart water management system which can cover potential risks of the current water distribution system.

\section{Acknowledgments}

This research was supported by a grant (12-TI-C01) from Advanced Water Management Research Program funded by the Ministry of Land, Infrastructure and Transport of Korean Government.

\section{Author Contributions}

Byeon led the work performance and wrote the manuscript; Choi and Gourbesville coordinated the research and contributed to writing the article; Byeon collected data and Maeng generated the result. All authors read and approved the final manuscript.

\section{Conflicts of Interest}

The authors declare no conflict of interest.

\section{References}

1. Park, H.S.; Choi, G.W. Applicability evaluation of RCP climate change scenarios in the complex coastal regions. Korean Rev. Crisis Emerg. Manag. 2014, 10, 215-230. (In Korean)

2. Cassardo, C.; Jones, J.A. Managing water in a changing world. Water 2011, 3, 618-628.

3. Chung, E.S.; Won, K.; Kim, Y.; Lee, H. Water resource vulnerability characteristics by district's population size in a changing climate using subjective and objective weights. Sustainability 2014, 6, 6141-6157. 
4. Jang, D.W.; Park, H.S.; Choi, G.W. Application of interpolation methods to estimate precipitation in coastal area using region climate change scenarios. In Proceedings of the 2014 International Conference on Civil Engineering, Energy and Environment 2014, Hong Kong, China, 13-14 December 2014.

5. Kim, E.; Ra, I.; Rhee, K.H.; Kim, C.S. Estimation of real-time flood risk on roads based on rainfall calculated by the revised method of missing rainfall. Sustainability 2014, 6, 6418-6431.

6. Syed, Z.H.; Han, M.S.; Choi, G.W. Evaluation of regional droughts using monthly gridded precipitation for Korean. J. Hydroinformat. 2012, 14, 1036-1050.

7. Incheon Free Economic Zone Official Website. Available online: http://www.ifez.go.kr/eng (accessed on 30 December 2014).

8. Korea Rural Community \& Agriculture Corporation Saemangeum Project Office Official Website. Available online: http://www.isaemangeum.co.kr (accessed on 30 December 2014).

9. Gourbesville, P. Hydroinformatics challenges and ways to overcome them. In Proceedings of the 11th International Conference on Hydroinformatics HIC 2014, New York, NY, USA, 17-21 August 2014.

10. Byeon, S.J.; Jung, J.K.; Choi, G.W.; Jang, D.W. A study on the improvements of smart water grid on water policy direction for local government. Korean Rev. Crisis Emerg. Manag. 2013, 9, $27-42$. (In Korean)

11. @qua. Maps of Water Business Process, @qua ICT for Water Efficiency; Sophia Antipolis: Nice, France, 2011.

12. Byeon, S.J.; Lee, S.H.; Choi, G.W.; Jung, J.K. Use of gauged water level and precipitation data to predict short term water level changes. Korean Rev. Crisis Emerg. Manag. 2014, 10, 247-264. (In Korean)

13. Holz, K-P.; Cunge, J.A.; Lehfeldt, R.; Savic, D. Hydroinformatics Vision 2011; Advances in Hydroinformatics: SIMHYDRO 2012-New Frontiers of Simulation; Springer: Singapore, 2012; pp. 545-560.

14. Jønch-Clausen T. Integrated Water Resources Management (IWRM) and Water Efficiency Plans by 2005; Global Water Patnership: Stockholm, Sweden, 2004.

15. Fulazzaky, M.A. Challenges of integrated water resources management in Indonesia. Water 2014, 6, 2000-2020.

16. Giupponi, C.; Sgobbi, A. Decision support system for water resources management in developing countries: Learning from experiences in Africa. Water 2013, 5, 798-818.

17. Horowitz, G. It's Time for the Smart Water Grid. Available online: http://bluetechblog.com/ 2010/06/02/it's-time-for-the-smart-water-grid/ (accessed on 11 January 2015).

18. Woo, D.S.; Kim, S.H.; Shin, S.H.; Kim, J.H.; Jung, J.T.; Choi, G.W. Water treatment process settings according to blending alternative resources in Smart Water Grid Research in Korea. In Proceedings of the Smart Water Grid International Conference 2013, Incheon, Korea, 12-14 November 2013 [CD-ROM]; Smart Water Grid Research Group: Incheon, Korea, 2013.

19. Gourbesville, P. ICT for Water Efficiency. Environmental Monitoring; Intech: Hampshire, UK, 2011.

20. Mutchek, M.; Williams, E. Moving towards sustainable and resilient smart water grids. Challenges 2014, 5, 123-137. 
21. Hauser, A. Risks for smart water applications: Rigorous risk assessment of the adoption of smart water applications. In Proceedings of the 2013 ISA Water/Wastewater and Automatic Controls Symposium, Orlando, FL, USA, 6-8 August 2013.

22. Holz, K.-P. Hydroinformatics contribution to smart water grid. In Proceedings of the Smart Water Grid International Conference 2013, Incheon, Korea, 12-14 November 2013 [CD-ROM]; Smart Water Grid Research Group: Incheon, Korea, 2013.

23. Incheon Free Economic Zone's official website, Available online: http://www.ifez.go.kr/eng/ en/m3/yj/screen.do (accessed on 10 January 2015)

24. Lee, Y.H. Study on Emergency Water Supply Alternatives in Cut off Water Supply-Prone Island Area. Master Thesis, Kyungpook National University, Daegu, Korea, 2013.

25. Incheon, J. Statistics Annual Report, in Korean; Incheon Metropolitan City Government: Incheon, Korea, 2012.

(C) 2015 by the authors; licensee MDPI, Basel, Switzerland. This article is an open access article distributed under the terms and conditions of the Creative Commons Attribution license (http://creativecommons.org/licenses/by/4.0/). 